\title{
Efeitos da idade da matriz leve e do período de armazenamento de ovos incubáveis no rendimento de incubação
}

\author{
[Effects of ages of light breeder hens and storage period of hatchable eggs on the incubation efficiency] \\ C.B.G.S. Tanure ${ }^{1}$, M.B. Café $^{2}$, N.S.M. Leandro ${ }^{2}$, N.C. Baião ${ }^{3}$, J.H. Stringhini ${ }^{2}$, N.A. Gomes ${ }^{1}$ \\ ${ }^{1}$ Aluna de pós-graduação - EV-UFG \\ Caixa Postal 131 \\ 74001-970 - Goiânia, GO \\ ${ }^{2}$ Escola de Veterinária - UFG - Goiânia, GO \\ ${ }^{3}$ Escola de Veterinária - UFMG - Belo Horizonte, MG
}

\begin{abstract}
RESUMO
Avaliaram-se os efeitos da idade das matrizes leves e do período de armazenamento dos ovos sobre o rendimento de incubação. Foram utilizados 7.224 ovos da linhagem Dekalb, distribuídos de acordo com delineamento experimental inteiramente casualizado, sendo a altura de bandeja uma covariável. Os tratamentos foram definidos pelas idades das matrizes (32 e 57 semanas de idade) e o período de armazenamento dos ovos (três, cinco e sete dias), totalizando seis tratamentos com 14 repetições. A idade das aves influenciou o peso do ovo. Houve aumento na perda de peso dos ovos das matrizes de 32 e 57 semanas de idade, durante o armazenamento (10,48 e 14,16\%, respectivamente) e na transferência (10,40 e $12,07 \%$, respectivamente). Verificou-se maior taxa de eclosão $(86,90 \%)$ em ovos produzidos pelas matrizes novas. Independentemente da idade da matriz, à medida que aumentou o período de armazenamento, houve diminuição na taxa de eclosão dos ovos férteis $(86,06$ e 82,39\%, para as matrizes de 32 e 57 semanas de idade, respectivamente). As matrizes com 57 semanas de idade produziram pintos mais pesados e com menor relação peso do pinto/peso do ovo.

Palavras-chave: matriz leve, armazenamento, incubação, ovos incubáveis
\end{abstract}

\begin{abstract}
The effects of ages of light breeder hens and storage period of hatchabe eggs on the incubation efficiency were evaluated. A total of 7,224 Dekalb hatching eggs were assigned according to the sample random design, and the hatching tray height was considered a co-variable. The treatments were defined according to the breeder hens ages (32 and 57-week-old) and the period of storage of eggs (three, five, and seven days), with 14 replications. The age of the hen affected the weight of the eggs. There was loss of weight of the eggs of 32 and 57-week-old breeder hens during storage $(10.48$ and $14.16 \%$, respectively) and transference (10.40 and 12.07\%, respectively) according to the aging of the breeder hen. Eggs produced by the younger breeder hens had a higher hatching rate; however, no matter the age of the breeder hen, there was a decrease of the hatching rate of fertile eggs $(86.06$ and $82.39 \%$, for the 32 and 57-week-old breeder hens, respectively) whenever the storage period was increased. The 57-weekold breeder hens produced heavier chicks and lower chick/egg weight coefficient.
\end{abstract}

Keywords: breeder hen, storage, incubation, fertile eggs

\section{INTRODUÇÃO}

As diferenças relacionadas à idade da matriz podem explicar por que pintainhas provenientes de matrizes jovens têm mortalidade aumentada e desempenho reduzido (Vieira e Moran Jr., 1998). Matrizes jovens produzem ovos menores com baixo rendimento de incubação e pintos de pior qualidade com menor peso à eclosão (Benton Jr. e Brake, 1996; Suarez et al., 1997). Com a idade da matriz, os ovos aumentam de tamanho e há

Recebido em 31 de março de 2009

Aceito em 29 de outubro de 2009

c.bergmann@gmail.com 
maior proporção de gema em relação ao albúmen, devido à maior capacidade das aves velhas de transferência de lipídeos para a gema dos ovos (Vieira e Moran Jr., 1998a; Peebles et al., 2000; Burnham et al., 2001). Há também a diminuição na espessura da casca pelo aumento do número e do diâmetro dos poros, favorecendo trocas gasosas, necessitando de maior umidade de incubação para dificultar a desidratação excessiva dos ovos (Hodgetts, 1985; Wilson, 1991; Rosa et al., 2002). A desidratação do ovo afeta diretamente o peso e a qualidade do pinto ao nascer (Tona et al., 2001).

A eclodibilidade e a qualidade do pintinho podem diminuir quando o período de estocagem dos ovos excede três dias, independentemente da temperatura, uma vez que ocorrem mudanças em certos aspectos físicos do ovo, que levam a uma diminuição da qualidade de albúmen (Meijerhof et al., 1994; Tona et al., 2001). Ovos provenientes de plantéis mais velhos devem ser incubados mais rapidamente do que os provenientes de plantéis jovens, pois as aves mais jovens produzem albúmen de melhor qualidade (Brake, 1996). Além disso, tem-se observado que o ovo estocado pode apresentar maior período de incubação e retardamento do desenvolvimento embrionário (Reis et al., 1997). Embriões no estágio embrionário de pré-gástrula na oviposição são menos aptos a suportar prolongados tempos de estocagem do que aqueles no estágio de gástrula, sendo que esse efeito pode ser diminuído com o aquecimento dos ovos após a postura. (Butler, 1991; Schimidt, 2002).

Desta forma, faz-se necessário entender a relação entre idade da matriz leve e armazenamento dos ovos para esclarecer os efeitos subsequentes sobre o embrião, pois a eclodibilidade e a qualidade do pintinho são influenciadas pelo tempo, pela temperatura e pela umidade de estocagem. Entretanto, há pouca informação científica relacionada às matrizes leves na avicultura industrial, sendo comum a utilização dos parâmetros de matrizes pesadas (Michalsky et al., 2005).

Com este trabalho, objetivou-se avaliar o efeito da incubação de acordo com a idade da matriz e o período de armazenamento dos ovos e a interação entre essas variáveis.

\section{MATERIAL E MÉTODOS}

Foram utilizados 7.224 ovos incubáveis de matrizes leves da linhagem Dekalb, produzidos no mesmo dia por dois lotes, de 32 e 57 semanas de idade. Os ovos foram visualmente selecionados e pesados individualmente para as categorias de peso de 52 a $57 \mathrm{~g}$ para matrizes novas, e de 59 a $68 \mathrm{~g}$ para matrizes velhas. Em seguida, foram colocados em bandejas para incubação, com capacidade para 86 ovos cada uma, devidamente identificadas por tratamento e pesadas individualmente. Nos dias três, cinco e sete de armazenamento, para se obter a média da perda de peso dos ovos, as bandejas de todos os tratamentos foram pesadas.

Antes da incubação, os ovos foram transferidos para um corredor de pré-aquecimento, localizado entre a sala de incubação e a recepção dos ovos, onde permaneceram por oito horas. A temperatura foi mantida entre 26 e $27^{\circ} \mathrm{C}$ e a UR entre 76,1 e $77 \%$.

Os ovos foram incubados em incubadora Casp M57 RE, com capacidade para 19.264 ovos cada, sob temperatura de $37,4^{\circ} \mathrm{C}$ e umidade relativa (UR) de 58\%. Foram utilizados três carrinhos de 14 andares com capacidade de quatro bandejas por andar, totalizando 56 bandejas por carrinho. Os carrinhos foram colocados na mesma posição na incubadora e seguiram a rotina normal de incubação.

A transferência dos ovos da incubadora para o nascedouro foi feita com 456 horas de incubação (19 dias) em retirada única, e todas as bandejas de incubação foram pesadas individualmente. As bandejas com ovos de todos os tratamentos foram colocadas em nascedouro único, modelo Casp 108 HR, com capacidade para 19.264 ovos, regulada para temperatura de $24^{\circ} \mathrm{C}$ e UR de $67 \%$. Neste local, os pintos nascidos foram sexados, contados e alojados em caixas identificadas de acordo com os tratamentos e repetições. A retirada dos pintos do nascedouro ocorreu com 510 horas (21 dias + seis horas) de incubação. Foram retirados aleatoriamente 60 pintos por tratamento para pesagem da ave e dos sacos vitelinos em balança com precisão de $0,01 \mathrm{~g}$.

O delineamento experimental foi inteiramente ao acaso, sendo a altura da bandeja uma covariável, em esquema fatorial $2 \times 3 \mathrm{com}$ duas idades de 
matrizes (32 e 57 semanas) e três períodos de armazenamento (três, cinco e sete dias), totalizando seis tratamentos.

As variáveis estudadas foram: peso dos ovos no dia da postura, perda de peso dos ovos no armazenamento e ao final do período de incubação, taxa de eclosão de ovos férteis, peso dos pintos e relação peso do pinto/peso do ovo.

Os resultados foram submetidos à análise de variância, e as médias comparadas pelo teste de Tukey (5\%) pelo procedimento GLM do SAS/1998.

\section{RESULTADOS E DISCUSSÃO}

$\mathrm{Na}$ Tab. 1, estão dispostos os dados relacionados ao peso dos ovos no dia da postura e a perda de peso dos ovos durante o armazenamento. À medida que aumentou a idade da matriz, houve também aumento no peso do ovo $(\mathrm{P}<0,05)$ como anteriormente relatado por Rocha et al. (2006) que justificaram os achados pela baixa capacidade das reprodutoras jovens de transferir lipídios para a gema dos ovos.

Tabela 1. Peso dos ovos (g) de matrizes leves segundo as semanas de idade no dia da postura e perda de peso durante o armazenamento

\begin{tabular}{ccccc}
\hline Idade & Peso & \multicolumn{3}{c}{ Período de armazenamento (dias) } \\
\cline { 2 - 5 } (semanas) & do ovo & 3 & 5 & 7 \\
\hline 32 & $56,22 \mathrm{~B}$ & $0,42 \mathrm{cB}$ & $0,73 \mathrm{bB}$ & $1,13 \mathrm{Ab}$ \\
57 & $63,32 \mathrm{~A}$ & $0,48 \mathrm{cA}$ & $0,84 \mathrm{bA}$ & $1,25 \mathrm{aA}$ \\
\hline
\end{tabular}

Médias seguidas de letras distintas minúsculas na linha e maiúsculas na coluna diferem entre si $(\mathrm{P}>0,05)$ pelo Teste Tukey. CV $=0,83 \%$ (peso do ovo) e $14,8 \%$ (período de armazenamento).

A maior perda de peso na incubação para ovos produzidos por matrizes velhas pode ser justificada pela maior porosidade e menor espessura da casca, pois ambas estão negativamente correlacionadas com a taxa de perda de água dos ovos de matrizes (Roque e Soares ,1994; Santos, 2003). A maior perda de água, com $\mathrm{o}$ aumento do período de armazenamento, foi semelhante ao resultado encontrado por Ferreira et al. (2006) que, em estudo realizado com matrizes pesadas da linhagem Cobb (33 e 58 semanas de idade), concluíram que a maior perda de peso foi para os ovos produzidos pelas aves mais velhas com oito dias de armazenamento.
$\mathrm{Na}$ Tab. 2, estão apresentados os resultados relacionados à perda de peso dos ovos ao final do período de incubação (18 dias de incubação). Independente do período de armazenamento, ovos produzidos por matrizes de 57 semanas de idade perderam mais peso, o que pode ser explicado pela menor espessura da casca dos ovos comparado com matrizes jovens. Para matrizes pesadas, a perda de peso dos ovos incubáveis deve ser de aproximadamente $12 \%$ aos 18 dias de incubação para se alcançar melhores índices de eclodibilidade (Tullett, 1990; Brake, 1996; Rosa et al., 1999).

Tabela 2. Perda de peso dos ovos (\%) de matrizes leves ao final do período de incubação de acordo com a idade das matrizes leves e o período de armazenamento

\begin{tabular}{cccc}
\hline Idade & \multicolumn{3}{c}{ Período de armazenamento (dias) } \\
\cline { 2 - 4 }$($ semanas $)$ & 3 & 5 & 7 \\
\hline 32 & $10,31 \mathrm{bB}$ & $10,62 \mathrm{aB}$ & $10,28 \mathrm{abB}$ \\
57 & $11,54 \mathrm{bA}$ & $12,49 \mathrm{aA}$ & $12,19 \mathrm{abA}$ \\
\hline
\end{tabular}

Médias seguidas de letras distintas na linha e maiúsculas na coluna diferem $(\mathrm{P}>0,05)$ pelo Teste Tukey. CV = 4,5\%.

As taxas de eclosão em relação ao número de ovos férteis estão apresentadas na Tab. 3. As melhores taxas de eclosão foram obtidas pelas reprodutoras de 32 semanas de idade quando comparados aos ovos de matrizes com 57 semanas $(\mathrm{P}<0,05)$. A maior eclodibilidade para ovos de matrizes novas pode ser explicada pela piora na qualidade da casca associada ao aumento da idade da matriz, determinando a elevação na taxa de mortalidade embrionária e reduzindo o rendimento da incubação (Tullet, 1990; Rosa e Ávila, 2000). 
Houve influência do período de armazenamento nas taxas de eclosão para matrizes jovens e velhas, pois, à medida que se aumentou o período de armazenamento, a eclosão de ovos férteis diminuiu. Estes resultados assemelham-se aos descritos por Meijerhof et al. (1994) e Ferreira et al. (2006) que relataram redução da taxa de eclosão dos ovos férteis de acordo com o aumento do período de armazenamento, independentemente da idade da matriz. O ovo estocado requer maior período de incubação e apresenta retardamento do desenvolvimento embrionário (Reis et al., 1997 ).

Tabela 3. Taxa de eclosão (\%) dos ovos férteis de matrizes leves de acordo com a idade e o período de armazenamento $(3,5$ e 7 dias $)$

\begin{tabular}{cccc}
\hline & Idade & & \multicolumn{2}{c}{ Período de armazenamento (dias) } \\
\cline { 3 - 4 } (semanas) & 3 & 5 & 7 \\
\hline 32 & $87,37 \mathrm{aA}$ & $87,27 \mathrm{aA}$ & $86,06 \mathrm{Ba}$ \\
57 & $85,63 \mathrm{aB}$ & $84,45 \mathrm{aB}$ & $82,39 \mathrm{bB}$ \\
\hline
\end{tabular}

Médias seguidas de letras distintas minúsculas na linha e maiúsculas na coluna diferem entre si $(\mathrm{P}>0,05)$ pelo Teste Tukey. $\mathrm{CV}=6,0 \%$.

A Tab. 4 dispõe os dados das médias dos pesos dos ovos e dos pintos e as relações entre os pesos dos pintos e os pesos dos ovos. Houve relação positiva entre idade da matriz e peso do ovo e do pinto, ou seja, aves mais velhas produziram ovos com maiores pesos que eclodiram pintos mais pesados. Estes achados são semelhantes aos encontrados por Vieira e Moran Jr. (1998a); Bruzual et al. (2000); Luquetti et al. (2004); Rocha et al. (2006).
Observou-se que, com o aumento do período de armazenamento, o peso do pinto aumentou $(\mathrm{P}<0,05)$, o que pode ser atribuído à menor perda de água pelos ovos durante a incubação, pois a perda de água atrasaria alguns processos bioquímicos e limitaria o crescimento dos embriões (Roque e Soares, 1994). O peso dos pintos de matrizes novas e velhas com cinco dias de armazenamento foi semelhante aos de três e sete dias $(\mathrm{P}>0,05)$ de armazenamento.

Tabela 4. Peso médio do ovo e do pintinho e relação entre eles de acordo com a idade da matriz leve e o período de armazenamento

\begin{tabular}{|c|c|c|c|c|}
\hline \multirow{2}{*}{ Idade (semanas) } & \multicolumn{3}{|c|}{ Armazenamento (dias) } & \multirow[t]{2}{*}{ Média } \\
\hline & 3 & 5 & 7 & \\
\hline \multicolumn{5}{|c|}{ Peso do ovo (g) } \\
\hline 32 & 56,34 & 56,17 & 56,16 & $56,22 \mathrm{~B}$ \\
\hline 57 & 63,67 & 63,93 & 64,45 & $63,32 \mathrm{~A}$ \\
\hline Média & 60,01 & 60,05 & 60,30 & $\mathrm{CV}(\%)=0,83$ \\
\hline \multicolumn{5}{|c|}{ Peso do pinto (g) } \\
\hline 32 & $38,35 \mathrm{bB}$ & $39,09 \mathrm{abB}$ & $38,86 \mathrm{aB}$ & 38,77 \\
\hline 57 & $42,97 \mathrm{bA}$ & $43,80 \mathrm{abA}$ & $43,36 \mathrm{aA}$ & 43,38 \\
\hline Média & 40,66 & 41,45 & 41,12 & $\mathrm{CV}(\%)=4,79$ \\
\hline \multicolumn{5}{|c|}{ Relação peso do pinto/peso do ovo } \\
\hline 32 & 69,6 & 69,34 & 69,79 & $69,57 \mathrm{~A}$ \\
\hline 57 & 68,85 & 68,86 & 68,6 & $68,77 \mathrm{~B}$ \\
\hline Média & 69,22 & 69,10 & 69,19 & $\mathrm{CV}(\%)=1,54$ \\
\hline
\end{tabular}

Médias seguidas de letras distintas minúsculas na linha e maiúsculas na coluna diferem entre si $(\mathrm{P}>0,05)$ pelo Teste Tukey.

Os valores da relação do peso do pinto e o peso do ovo foram superiores para matrizes novas $(\mathrm{P}<0,05)$, sendo a média dessa relação correspondente a $68 \%$ do peso inicial do ovo
(Wilson, 1991). Este comportamento sugere que a perda de peso dos ovos ocorrida no período de incubação seja responsável pela menor relação peso do pinto/peso do ovo pelas matrizes velhas 
(Wilson, 1991; Michalsky et al., 2005; Joseph e Moran Jr., 2005). O período de armazenamento dos ovos não influenciou $(\mathrm{P}>0,05)$ a relação peso do pinto/peso do ovo, todavia observou-se maior valor para as aves com 32 semanas de idade.

\section{CONCLUSÕES}

A idade da matriz influencia a perda de peso dos ovos incubáveis durante o armazenamento e na transferência para a incubadora, sendo os maiores valores encontrados para ovos de matrizes mais velhas com maior período de armazenagem. O aumento no período de armazenamento influencia negativamente a eclodibilidade, especialmente para matrizes mais velhas.

\section{AGRADECIMENTOS}

À Granja Planalto, pelas aves cedidas para a realização do estudo. À CAPES, pela bolsa de estudos concedida.

\section{REFERÊNCIAS BIBLIOGRÁFICAS}

BENTON Jr., C.E.; BRAKE, J. The effect of broiler breeder age and length of egg storage on egg albumen during early incubation. Poult. Sci., v.75, p.1069-1075, 1996.

BRAKE, J.T. Optimization of egg handling and storage. World Poult., v.12, p.6-9, 1996.

BRUZUAL, J.J.; PEAK, S.D.; BRAKE, J. et al. Effects of relative humidity during incubation on hatchability and body weight of broiler chicks from young breeder flocks. Poult. Sci., v.79, p.827-830, 2000.

BURNHAM, M.R.; PEEBLES, E.D.; GARDNER, C.W. Effects of incubator humidity and hen age on yolk composition in broiler hatching eggs from young breeders. Poult. Sci., v.80, p.1444-1450, 2001

BUTLER, D.E. Egg handling and storage at the farm and hatchery. In: TULLETT, S.G. (Ed.). Avian incubation. London: ButterworthHeinemann, p.195-203, 1991.

FERREIRA, F.C.; LARA, L.J.C.; BAIÃO, N.C. et al. Influência da idade da matriz e do período de armazenamento de ovos sobre o rendimento de incubação de matrizes pesadas. Rev. Bras. Cienc. Avic., v.8, supl., p.18, 2006.
HODGETTS, B. Egg quality and hatchability. Intern. Hatch. Pract., v.2, p.17-19, 1985.

JOSEPH, N.S.; MORAN JR., E.T. Characteristics of eggs, embryos, and chicks from broiler breeder hens selected for growth or meat yield. J. Appl. Poult. Res., v.14, p.275-280, 2005.

LUQUETTI, B.C.; GONZALEZ, E.; BRUNO, L.D.G. Egg traits and physiological neonatal chick parameters from broiler breeder at different ages. Rev. Bras. Cienc. Avic., v.6, p.13-17, 2004.

MEIJERHOF, R.; NOORDHUIZEN, J.P.T.M.; LEENSTRA, F.R. Influence of preincubation treatment on hatching results of broiler breeder eggs produced at 37 and 59 weeks of age. $\mathrm{Br}$. Poult. Sci., v.35, p.249-257, 1994.

MICHALSKY, V.B.; CANÇADO, S.V.;LARA, L.J.C. et al. Influência da umidade na incubação e idade da matriz leve sobre a eclosão e parâmetros de ovos e pintos. Rev. Bras. Cienc. Avic., v.7, supl., p.13, 2005.

PEEBLES, E.D.; ZUMWALT, C.D.; DOYLE, S.M. et al. Effects of breeder age and dietary fat source and level on broiler breeder performance. Poult. Sci., v.79, p.629-639, 2000.

REIS, L.H.; GAMA, L.T.; SOARES, M.C. Effects of short storage conditions and broiler breeder age on hatchability, hatching time, and chick weights. Poult. Sci., v.76, p.1459-1466, 1997

ROCHA, J.S.R.; BAIÃO, N.C.; LARA, L.J.C. et al. Efeitos da idade da matriz e peso do ovo sobre componentes dos ovos e as relações peso do pinto/peso do ovo e peso do saco vitelino/peso do pinto. Rev. Bras. Cienc. Avic., v.8, supl., p.15, 2006

ROSA, P.S.; SCHEUERMANN, G.N.; FIGUEIREDO, E.A.P. Influência da umidade na incubadora sobre o desempenho de incubação em ovos com diferentes densidades específicas. In: CONFERÊNCIA APINCO DE CIÊNCIA E TECNOLOGIA AVÍCOLAS, 1999, Campinas. Anais... Campinas: FACTA, 1999. p.10.

ROSA, P. S.; ÁVILA, V. S. Variáveis relacionadas ao rendimento da incubação de ovos em matrizes de frango de corte. Concórdia: Embrapa Suínos e Aves, 2000, 3p. (comunicado técnico, 246). 
ROSA, P.S.; GUIDONI, A.L.; LIMA, I.L. Influência da temperatura de incubação em ovos de matrizes de corte com diferentes idades e classificados por peso sobre os resultados de incubação. Rev. Bras. Zootec., v.31, p.10111016, 2002.

ROQUE, L.; SOARES, M.C. Effects of eggshell and broiler breeder age on hatchability. Poult. Sci., v.73, p.1838-1845, 1994.

SANTOS, G.C.F. Efeito de linhagem e idade de reprodutoras pesadas e leves sobre a perda de umidade de ovos incubáveis aos 18 dias de incubação, submetidos a diferentes percentuais de umidade relativa. 2003. 17f. Monografia (Pós-graduação "lato-sensu" em Ciências Aviárias) - Faculdade de Medicina Veterinária, Universidade Federal de Uberlândia, Uberlândia, MG.

SCHMIDT, G.S.; FIGUEIREDO, E.A.P.; AVILA, V.S. Incubação: estocagem de ovos férteis. Concórdia: Embrapa Suínos e Aves, 2002. 5p. (comunicado técnico, 303).
SUAREZ, M.E.; WILSON, H.R.; MATHER, F.B. et al. Effect of strain and age of the broiler breeder female on incubation time and chick weight. Poult. Sci., v.76, p.1029-1036, 1997.

TONA, K.; BAMELIS, F.; COUCKE, W. et al. Relationship between broiler breeder's age and egg weight loss and embryonic mortality during incubation in large-scale conditions. J. Appl. Poult. Res., v.10, p.221-227, 2001.

TULLETT, S.G. Science and the art of incubation. Poult. Sci., v.69, p.1-15, 1990.

VIEIRA, S.L.; MORAN JR., E.T. Eggs and chicks from broiler breeders of extremely different age. J. Appl. Poult. Res., v.7, p.372376, 1998.

VIEIRA, S.L.; MORAN JR., E.T. Broiler yields using chicks from extremes in breeder age and dietary propionate. J. Appl. Poult. Res., v.7, p.320-327, 1998a.

WILSON, H.R. Interrelationships of egg size, chick size, posthatching growth, and hatchability. World Poult. Sci. J., v.47, p.5-20, 1991. 